\title{
Review Article \\ Drug Impairment and Liver Disease
}

\author{
SAHAR ATREES, Ph.D.* and HEBA MOHAMED RABIE, Ph.D.** \\ The Departments of Chemistry* and Zoology**, Faculty of Science, Fayoum University
}

\begin{abstract}
Abstract: Liver disease is a major cause of morbidity and mortality and is rated as one of the top 5 commonest causes of premature death in the world. However, not all liver problems are related to an underlying liver disease. Many patients have liver dysfunction which may be secondary to drug therapy, infections or sepsis, gallstones or trauma.

The liver helps purify the blood by changing potentially harmful chemicals into harmless ones, the sources of these chemicals can be outside the body, such as medications, or alcohol, or inside body, as ammonia and bilirubin. When drug injure the liver and disrupt its normal function, symptoms, signs. These drugs which called drug induced liver disease (DILI), leads to abnormal blood tests of liver disease, and also liver failure.
\end{abstract}

Liver failure occurs when large parts of the liver become damaged beyond repair, and the liver is no longer able to function, drug-induced liver injury (DILI), is the 4 th most important cause of liver disease in western countries, the incidence of DILI is between $1 / 10000$ and $1 / 100000$ patientsyears.

Aim of Study: Review the evidence regarding fundamental pharmacokinetics alterations caused by the liver disease as well as the potential foe liver toxicity with DILI. Analysis of the evidence of DILI and severe liver injury leading to death will be the aim, finally, provide recommendation and directions regarding drugs and how to minimize the risk of liver toxicity.

Key Words: Drug - Liver disease.

\section{Introduction}

A large number of drugs have been implicated as a potential cause of drug-induced hepatitis with $25-50 \%$ of all cases of hepatitis and hepatic failure assumed to be caused by adverse drug side effects and with about $15 \%$ of patients with autoimmune hepatitis also suffer from drug-induced liver disease

Correspondence to: Dr. Sahar Atrees,

E-Mail: ssa07@fayoum.edu.eg
[1-3]. The development of drug-induced liver disease is dependent on drug as well as individual patient's factors such as genetic predisposition, age and pre-existing liver disease [4]

Drug hepatotoxicity can be non-idiosyncratic (predictable), or idiosyncratic (unpredictable), about $10 \%$ of cases are idiosyncratic [5] .

Drug-induced hepatitis involves inflammation of the liver caused by medication, it is similar to acute viral hepatitis, but parenchymal destruction tends to be more extensive. Certain drugs can cause damage of liver in a variety of ways. These damages include acute hepatocellular damage, chronic active hepatitis, cirrhosis and other damages which are summarized with their induced drugs in (Table 1).

The liver is the major organ actively involved in metabolism and detoxification of drugs and xenobiotics. Drug metabolism can be divided into three phases. The phase I drug oxidation involves a super family of CYP monooxygenases. The major drug metabolizing P450 monooxygenase is CYP3A4, which accounts for $60 \%$ of P450 enzymes in the liver and metabolizes $70 \%$ of drugs in humans. Phase I reactions may activate prodrugs to the active forms and metabolize xenobiotics to nontoxic compounds, but in some, increases toxicity of the metabolites. The phase II reactions are conjugation reactions including sulfation, methylation, and glucuronidation to further increase the solubility of oxidized metabolites, which are secreted through the phase III drug transporters located in the membranes of hepatocytes, intestine cells, kidney, and other tissues for excretion out of the body. The phase I drug oxidation, phase II drug conjugation and phase III drug transport systems are induced by drugs and xenobiotics as seen in the following figure. 


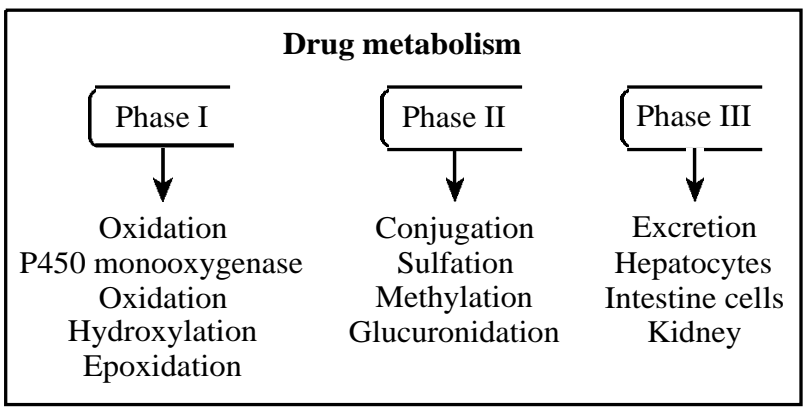

Fig. (1):

\section{Drug detoxification in liver:}

Liver failure interferes with different stages of pharmacokinetics: Absorption, metabolism, distribution and elimination which consequently affect drug concentrations, duration of action, and effectiveness. Therefore it is essential to be aware of these processes and consequent changes in the circulating concentration to prevent drug toxicity [7].

\section{Liver disease and pharmacokinetics changes:}

The liver is the organ by which the majority of substances are metabolized, including drugs. There are several pharmacokinetics changes in end-stage liver disease that can interfere with the metabolization of drugs. The evidence is insufficient for definite conclusions regarding the prevalence and severity of drugs-induced liver injury [7,8]

Liver failure can affect some aspects of medication pharmacokinetics, ranging from absorption to distribution and elimination. The most important pharmacokinetics process that might lead to increased drug concentrations in liver will be discussed below.

\section{Distribution:}

In end-stage liver disease, a great part of blood in portal vein escapes from liver and flows straight into systemic circulation (by means of portosystemic shunts). This process is due to intra-and extra-hepatic shunts that can occur. Therapeutic shunts (surgical and angiographic) can also be used to alleviate portal hypertension [8].

These shunts can affect first-pass metabolism by diminishing liver perfusion. In these cases, less drug passes through the liver before systemic distribution consequently, there is an elevation in drug concentrations in the blood. This effect is particularly important for drugs with extensive first-pass metabolism. Drugs, such as diazepam and paroxetine, with less affinity for liver enzymes, are not as influenced by first-pass metabolism [9]
Although olanzapine, antipsychotic drug, has great first-pass metabolism, it is mostly metabolized by second-phase liver metabolic processes (preserved in liver disease), so it might not be an important factor for this particular drug [10].

\section{Protein binding:}

More than $80 \%$ of drugs are bound to plasma proteins, such as lipoproteins, alpha 1-acidglycoprotein and albumin, some drugs, such as fluoxetine, aripiprazole and diazepam, are highly protein bound. Nevertheless, there are some drugs that minimally bind to proteins, such as venlafxine, lithium, topiramate, gabapentin, pregabain, methylphenidate and memantine [11-13]

In case of Cirrhosis, a smaller quantity of albumin and alpha 1 -acid-glycoprotein is produced, which is conductive to an increased concentration of free active drug in the blood [14]. This increase leads to more severe adverse effects from these drugs. Therefore, highly protein-bound drugs, such as benzodiazepines, (particularly diazepam, which is more than $99 \%$ protein bound) are practically important and are of higher risk [15]

\section{Metabolism:}

Some drugs are water soluble and are directly removed from the circulation in the urine and bile, which is the case of lithium, gabapentin and topiramate [11]. However, all of the other drugs are lipid soluble and are metabolized in the liver by some chemical changes to become more soluble, only then can be excreted in the urine or bile. The metabolic reactions that take place in the liver can occur in two phases [16], in phase 1, cytochrome $\mathrm{P}-450$ enzymes, monooxygenases, are responsible for the hydrolysis, oxidation, dealkylation or reduction of the molecule.

Most of the time, these reactions decrease the pharmacological activity of the substrate. However, drugs are sometimes metabolized into active metabolites, which is the case with some benzodiazepines, tricyclic antidepressants and antipsychotic [11]. In phase 11, liver enzymes are responsible for the conjugation of the drug with endogenous molecules, such as glucuronic acid, sulphate, aminoacids, acetate or glutathione. This process renders the original molecule more hydrophilic [16], and in most of the cases, it eliminates all of the pharmacological activity. Conjugation with glucuronic acid is normally preserved in liver disease [17] Therefore, it might be beneficial to select a drug that only requires glucuronidation, and does not require a phase 1 reaction, which is the case with 
temazepam, oxazepam, and lorazepam $[\mathbf{9 , 1 0}$. Olanzapine also requires almost only glucuronidation in its metabolization [10].

\section{Fluid statue:}

Although it is believed that water-soluble drugs, such as lithium, are safe to use in liver disease, there are some aspects that must be considered. In fact, it is not easy to maintain therapeutic serum levels of drugs such as lithium with the changes in fluid status that can occur in liver disease patients. These changes can be due to abnormal renal haemodynamics which is often seen in liver diseased patients, or due to any sudden change in fluid status during therapeutic procedures such as paracentesis, extreme diuresis, or diarrhoea induced in the treatment of liver encephalopathy [11]

\section{DILI classifications:}

DILI can be classified depending on different criteria: Pathophysiological mechanism, clinical evolution, underlying injury, and severity of the lesion, each of these criteria are reviewed.

\section{Underlying liver injury:}

DILI can be classified into three main categories according to the pattern of liver injury (i.e., hepatocellular and cholestatic or mixed). Hepatocellular injury accounts for $90 \%$ of drug-induced hepatotoxicity and is associated with abnormally high serum alanine aminotransferase (ALT) titers, with a small or no increase in Alkaline Phosphatase (ALP) titers; an associated high serum bilirubin level, found in cases of severe hepatocellular damage, is a marker for poor prognosis [18]. Cholestasis liver injury is associated with high serum ALP titers only slightly higher than normal ALT levels; serum bilirubin concentrations might also be high. In cases of mixed injury, both ALT and ALP levels are abnormally high.

Another type of lesion is steatosis. This reaction is generally chronic and occurs with gradual and increased fat accumulation in the liver (especially triglycerides), which can be caused by different situations, including the use of certain drugs. In drug-induced steatosis benign macrovacular steatosis can become steatohepatitis and cirrhosis in some cases.

Steatosis can occur with exposure to some antipsychotic as clozapine, and olanzapine,or antiepileptic as valproate [19]. Also steatosis can be form of serious of deposition of fat in hepatocytes, associates with more severe clinical consequences.

\section{Pathophysiological types of DILI:}

Two pathophysiological types of DILI, the most common type is idiosyncratic, dose-independent and unpredictable [20]. It is the consequence either of immune-mediated liver damage (immunoallergic idiosyncratic DILI), or of direct cellular injury (metabolic idiosyncratic DILI), Hypersensitivity syndrome and short latency period from one to six weeks suggest immune-mediated hepatic injury [21]. Whereas the absence of any hypersensitivity syndrome and a longer latency period over year, suggest an idiosyncratic metabolic mechanism [21] Intrinsic DILI, related to drug accumulation, has also been described; it is dose dependent and predictable.

\section{Clinical evolution:}

DILI can be acute or chronic, depending on clinical presentation, acute DILI is the most common form of DILI, accounting for $10 \%$ of all cases of acute hepatitis. Histologically, it can present as acute hepatitis, cholestasis injury, a mixed pattern or acute steatosis. Chronic DILI is definite as persistence of abnormal liver enzymes for more than 6 month, and it accounts for $10 \%$ of DILI cases [22]

\section{Severity of DILI:}

Regarding its severity, DILI can be mild, severe, or fatal. According to the Drug-Induced Liver Injury Network (DILIN), in mild DILI, is elevation of ALT and/or ALP, but no important increase in bilirubin and no impairment of coagulation. In Severe DILI, is elevation of ALT and/or ALP, bilirubin is also increased and extended jaundice for more than three months; and liver and other organ failure induced by the drug. In fatal, DILI, death occurs [23].

Detection of DILI during clinical trials is difficult challenge because of the small number of patients treated and short duration of the majority of clinical trials (6-12wks.) relative to the latency of DILI [24].

Antidepressants associated DILI is generally of the hepatocellular type and less frequently of the cholestatic or mixed type [25]. Concerning pathophysiology, it can be immunoallergic or metabolic, various biological and clinical presentation are possible, ranging from increase liver enzymes to loss hepatocellular function, acute renal failure and death [26]. Table (2) summarizes the data on hepatotoxicity of main drugs. 
Table (1): Summarize drugs and chemically related to liver damage.

\begin{tabular}{|c|c|c|}
\hline Disease & Dose-related liver damage & Dose-unrelated liver damage \\
\hline 1- Acute hepatocellular damage & $\begin{array}{l}\text { Alcohol } \\
\text { Paracetamol poisoning } \\
\text { Amidodarone } \\
\text { Methotrexate } \\
\text { Azathioprine }\end{array}$ & $\begin{array}{l}\text { Antituberculous } \\
\text { Halothane } \\
\text { Anticonvulsants (phenytoin, carbamazapin, and valproate) } \\
\text { Azathioprin [6] }\end{array}$ \\
\hline 2- Chronic hepatitis & Isoniazid & Nitrofurantoin \\
\hline 3- Cirrhosis & $\begin{array}{l}\text { Alcohol } \\
\text { Methotrexate }\end{array}$ & Erythomycin \\
\hline 4- Hepatic tumors & $\begin{array}{l}\text { Anabolic steroids } \\
\text { Combined oral contraceptives }\end{array}$ & $\begin{array}{l}\text { Methotrexate } \\
\text { Trabectedin } \\
\text { Ozogamicin Cyclophosphamide }\end{array}$ \\
\hline 5- Intrahepatic cholestasis & $\begin{array}{l}\text { Anabolic steroids } \\
\text { Azathioprine } \\
\text { Oestrogens }\end{array}$ & $\begin{array}{l}\text { Carbimazole } \\
\text { Erythromyocine Phenothiazines }\end{array}$ \\
\hline 6- Gallstones & $\begin{array}{l}\text { Clofibrates, } \\
\text { Oestrogens }\end{array}$ & Antibiotics (erythromycin, ampicillin) \\
\hline
\end{tabular}

Table (2): DILI drugs and liver toxicity.

\begin{tabular}{|c|c|c|c|}
\hline DILI & Epidemiology & Type of lesion & Mechanism \\
\hline \multicolumn{4}{|l|}{ Anti-depressants: } \\
\hline Amitriptyline & Fatal DILI [27] & Hepatocellular Cholestatic & Immune-Allergic \\
\hline Sertraline & ALT $>3 \mathrm{ULN}: 0.5 \%[28]$ & Hepatocellular & Immune-Allergic \\
\hline \multirow[t]{2}{*}{ Paroxetine } & DILI: $1.28 / 100000$ & Mixed hepatocellular + cholestatic & Immune-Allergic \\
\hline & $\mathrm{ALT}>3 \mathrm{ULN}: 1 \%[28]$ & Hepatocellular & Immune-Allergic \\
\hline Trazodone & Severe DILI: 7 [26] & & \\
\hline \multicolumn{4}{|l|}{ Anti-convulasants: } \\
\hline Bupropion & ALT $>3$ ULN: $1 \%[29]$ & Hepatocellular & Immune \\
\hline \multirow[t]{2}{*}{ Mirtazapine } & ALT $>3$ ULN: $2 \%$ & Hepatocellular & Immune \\
\hline & Severe DILI: 2 [29] & Hepatocellular & Metabolic \\
\hline \multirow[t]{2}{*}{ Valproate } & Transient, ALT, AST-61\% & & \\
\hline & Elevation [2] & & \\
\hline \multicolumn{4}{|l|}{ Anti -psychotic: } \\
\hline \multirow[t]{2}{*}{ Cloropromazine } & Jaundice- $0.16 \%$ & Hepatocellular & Chronic steatosis \\
\hline & Severe DILI: 350 [30] & Steatosis cholestasis & Chronic-steatosis \\
\hline \multirow[t]{2}{*}{ Olanzapine } & ALT $>3$ ULN: $6 \%$ & Cholestatic steatosis & Immune chronic steatosis \\
\hline & Severe DILI: 7 [31] & & \\
\hline \multirow[t]{2}{*}{ Risperidone } & ALT > ULN: $3 \%[32]$ & & \\
\hline & Severe DILI: 13 & & \\
\hline \multicolumn{4}{|l|}{ Anti-epileptics: } \\
\hline Carbamazepine & Transient ALT, AST, GGT elevation & Hepatocellular cholestasis & Hypersensitivity \\
\hline Gabapentine & $61 \%$, rare hepatotoxicity, $[34]$ & & metabolic [33] \\
\hline Topiramate & Transient, ALT, AST elevation & Hepatocellular & Metabolic Toxic \\
\hline \multicolumn{4}{|l|}{ Benzodiazepine: } \\
\hline Diazepam & Rare hepatotoxic & Cholestatic [35] & Hypersensitivity \\
\hline Furazepam & Rare hepatotoxic & & \\
\hline Lithium & Very rare hepatotoxic [2] & & \\
\hline
\end{tabular}

DILI : Drug-Induced Liver Injury.

ALT : Alanine Aminotransferase.

AST : Aspartate Aminotransferase.
GGT : Gama Glutamy Transferase.

ULN : Upper Normal Limit. 
Valproate is associated with risk of liver toxicity; valproate is generally idiosyncratic, Table (2). The period of treatment before the onset of the injury can range from 3 to 2 years. The absence of hypersensitivity syndrome, the morphology of the DILI and the slow onset suggest that the idiosyncrasy is metabolic. It is more common in infants and children [36].

Valproate cause elevation of transaminases in $10 \%$ to $15 \%$ of patients and hyperbilirubinemia in up $44 \%$. sometimes, normalization of liver occurs because of adpatation [37]. Anthers DILI, carbamazepine, Table (2), hepatic adverse events are frequent but are most represented by asymptotic elevations in liver tests (ALT, ALP, GGT). Severe liver damage caused by carbamazepine is infrequent, but it has a very presentation, (1-8wks.) after beginning treatment with this drug.

Benzodiazepine-induced liver damage, Table (2), is rare, with few reported cases, generally with a cholestasis [35].

Long term treatment with lithium can, induce some liver function tests abnormalities, these changes are temporarily and asymptomatic. with lithium overdose, liver function tests was changed markedly, although the damage is much more severe in other organs as kidney [2]

\section{Conclusion and Recommendation:}

The available data on drug-induced hepatic toxicity are from reported cases and results of clinical trials and other studies for the most recent drugs it is difficult to draw conclusion about prevalence and severity of DILI.

Regarding pharmacokinetic changes in liver disease, there are some drugs that require special attention, as shown in (Table 3).

Table (3): Pharmacokinetics changes caused by drugs in liver.

\begin{tabular}{|c|c|}
\hline $\begin{array}{l}\text { - Avoid drugs with } \\
\text { extensive first- } \\
\text { pass metabolism }\end{array}$ & $\begin{array}{l}\text { - Tricyclic antidepressants-first pass } \\
\text { metabolism } 50 \% \text {, venlafaxine, } \\
\text { sertraline, bupropion }\end{array}$ \\
\hline $\begin{array}{l}\text { - Avoid highly } \\
\text { protein bound } \\
\text { drugs }\end{array}$ & $\begin{array}{l}\text { - Most psychotropic drugs, fluoxetine, } \\
\text { etc., }\end{array}$ \\
\hline $\begin{array}{l}\text { - Avoid drugs } \\
\text { depend on phase } \\
1 \text { hepatic } \\
\text { metabolism }\end{array}$ & $\begin{array}{l}\text { Preferable, lithium, gabapentin, } \\
\text { depend on renal excretion, } \\
\text { benzodiazepines, as temazepam, } \\
\text { lorazepam depend on phase } 11 \\
\text { reaction, which preservedin, cirrhosis }\end{array}$ \\
\hline
\end{tabular}

Hepatic reserve is reduced in patients with cirrhosis or chronic hepatic failure, and when DILI occurs in such patients, it can be more severe [38]
Therfore high risk drugs should be contraindicated in cases of pre-existing liver disease [39].

Before starting a drug, baseline laboratory testing (e.g., LFT, ALT) is recommended, if liver disease is present, it is preferable to use drugs with minimal liver metabolism (e.g., topiramate, sulpride), after start a drug, frequent liver function and lesion monitoring is advised, [40]

In the cases of normal lab tests before initiating treatment, there is no clear unanimity regarding the frequency of analysis re-assessment. laboratory tests with ALT more than 3 ULN or ALP more than 2 ULN are considered sensitive markers for liver damage, and in these cases, the drug should be stopped, [41].

Acetaminophen, is extremely safe even for people with liver disease, however, taking too much acetaminophen at once or high dose over several days can cause damage to liver, even if you have no liver disease, always use smallest amount of acetaminophen needed to obtain relief.

Statins, cholesterol lowering drugs, have been used in millions of people with excellent safety record and very little evidence of liver damage, people with mild liver disease, develop minor elevations of liver tests soon after the starting taking these medications, in the vast majority of cases, these elevations are less than 3 times the baseline level and the levels return to normal despite continued use of medications, when starting a patient on statins, if the liver tests are monitored, the medication should not be stopped if only minor elevations of liver tests are noted.

At last, after start a drug report signs and symptoms of liver dysfunction should be counseled. Including weight loss/decrease appetite, gastrointestinal problems or changes, dark urine, yellowish of eyes, weakness, or unexplained fatigue. other signs include pruritus, clay-colored stool, muscle pain, and increased confusion. Some of these conditions are already associated with chronic hepatitis infection, so it is important to emphasis observations of new-onset observation to their clinicians should they occur at any time after starting a drug. Prompt discontinuation of the suspected drug at symptom onset might decrease the likelihood of worsening progression, which can lead to permanent liver damage, [42]

Many researches should be made on drugs manipulative with other forms with preserve their ingredients, such as nanoparticles instead of full tablets, or effervescences particles taken orally, 
emulsifications, or new forms of up taken drugs that preserve the effective material but change the ways of its metabolites, will be very helpful for reduce the toxicity of DILI.

Also, more research needs to be done to understand the long term safety and effectiveness of the drugs.

\section{References}

1- RYAN Y.H., DERON R.H. and SHABBIA M.: Microorganisms, 8: 773. doi: 10.3390/microorganism 8050773, 2020.

2- SCHUSTER D., LAGGNER C. and LAGNER T.: Why drugs fail-a study on effects in new chemical entities. Curr. Pharm. Des., 11: 3545-59, 2005.

3- YEONG T.T., LIM K.H., GOUBET S., et al.: Natural history and outcomes in drug-induced autoimmune hepatitis. Hepatol. Res., May 5. doi: 10. 111 1/hepr. 12532, 2015.

4- COLIN T.: Drug induced hepatitis. gastroenerology. Vol. 35, 697-905. http://patient.info/doctor/drug-inducedhepatitis, 2020.

5- WEILER S., MERZ M. and KULLAK-UBLICK G.A. Drug induced liver injury: The dawn of biomarkers/F 1000prime Rep. Mar. 37: 34. doi: 10.12703/p 7-34. Ecollection 2015.

6- LO RE V. 3rd, HAYNES K., FORDEL K.A., et al.: Clin. Gastroenterol. Hepatol., Pii: s 1542-3565 (15) 00844-7. doi: 10. 1016/j. cgh. 2015.06.020, 2015.

7- TELLES-CORREEIA D., et al.: World J. Gastrointest. Pharmacol. Ther., 8: 26-38, 2017.

8- POWELL D.W.: Approach to the patients with liver disease. Cecil Textbook of medicine. 21 ed. Philadelphia: Saunders: 767-8, 2000.

9- HOWDEN C.W., BIRNIE G.G. and BRODIE M.J.: Drug metabolism in liver disease. Pharmacol. Ther., 40: 43974, 1989.

10- WITHERS N.: The liver -impaired patient. Handbook of Consultation Liason Physchiatry. New York Spring, 24869, 2008.

11- STEVENS J., FAVA M., ROSENBAUM J. and ALPERT J.: Psychopharmacology in the medical setting. Handbook of General Hospital Psychiatry. 6 ed. Philadelphia: Saunders Elsevier, 2010.

12-DEVANE C.L., SAVETT M. \& JUSKO W.J.: Desipramine and 2-hydroxy-despiramine pharmacokinetics in normal volunteers. Eurr. J. Clin. Pharmacol., 19: 61-4, 1981.

13- SCHROEDER D.H.: Metabolism and kinetics of bupropion. J. Clin. Psychiatry, 44: 79-81, 1983.

14- BLASCHKE T.F.: Protein binding and kienetics of drugs in liver disease. Clin. Pharmacokinet., 2: 32:44, 1977.

15- DOWEIKO H.: Concepts of chemical dependency. 8 ed. Belmont: Books/Cole, 2009.

16- ADEDOYIN A. and BRANCH R.A.: Pharmacokuinetics. Hepatology: A textbook of liver disease. 3 ed, Philadelphia: Saunders elsevere, 1996.
17- CRONE C.C., GABRIEL G.M. and DIMARTINI A.: Psychosomatics, 47: 188-205, 2006.

18- AITHAL G.P., WATKINS P.B., ANDRADE R.J., LARREY D., et al.: Case definition and phenotype stanarization in drug indued liver injury. Clin. Pharmacol. Ther., 89: 806-15, 2011

19-ZHANG X., OUYANG J. and THUNG S.: Histopathologic manifestations of drug induced hepatotoxicity. Clinics Review Articles. Drug hepatotoxicity, 547-59, 2013.

20- LAMMERT C., EINARS SON S., SAHA C., et al.: Relationship between daily dose of oral medications and idiosyncratic drug-induced liver injury: Search for signals hepatology, 47: 2003-9, 2008.

21- KAPLOWITZ N.: Idiosyncratic drug hepatotoxicity. Nalt. Rev. Drug Discov., 4: 489-99, 2005.

22- MARK D. and HARBORD M.: Emergencies in gastroenterology and hepatology. Oxford: Oxford University Press, 2013.

23- FONTANA R.J., SEEFF L.B., et al.: Hepatology, 52: 73042, 2010.

24- KORAN L.M., GELENBERG A.J., et al.: Sertraline versus impairmine to prevent relapse in chronic depression. J. Affect Discord, 65: 27: 36, 2001.

25- ANDRADE R.J., et al.: Drug-induced liver injury: An analysis of 461 incidence submitted to Spanish registry over a 10 year-period. Gastroenterology, 129: 512-21, 2005.

26- VOICAN C.S., CORRUBLE E., NAVEAU S. and PERIEMUTER G.: Antidepressant-induced liver injury: A review for clinicans. Am. J. Psychiatry, 171: 404-15, 2014.

27- RANDEVA H.S., BANGAR V., SAILESH S. and HILLHOUSE E.V.: J. Clin. Psychopharmacol., 24: 353-4, 2000.

28- CARVAJAL GARCIA-PANDO A., et al.: Hepatotoxicity associated with new antidepressants. J. Clin. Psychiatry, 63: 135-7, 2002.

29- HU K.Q., TIYYAGURA L., KANEL G. and REDEKER A.G.: Acute hepatitis induced by bupropion. Dig. Dis. Sci., 45: 1872-3, 2000.

30- DERBY L.E., GUTHANN S.P., JICK H. and DEAN A.D.: Liver disorders in patients receving cgloropromazine or isoniazid. Pharmacotherapy, 13: 353-8, 1999.

31- ATASOY N., ERDOGAN A., YALUG I., OZTURK U., KONUK N. and ATIK L.: A review of liver function tests during treatment with atypical antipsychotic drugs. Prog. Neuropsychopharmacol. Biol. Psychiatry, 31: 1255-60, 2007.

32- PAE C.U., et al.: Int. Clin. Psychopharmacol., 20: 1736, 2005.

33- AU J.S. and POCKROS P.J.: Drug-induced liver injury from antiepileptic drugs. Clin. Liver Dis., 13: 687-97, 2013.

34- AHMED S.N. and SIDDIQI Z.A.: Seizure, 15: 156-64, 2005.

35- ANDRADE R.J., LUCENA M.I., ALCANTARA R. and FRAILE J.M.: Lancet, 343: 860, 1994.

36- ERDOGAN A., et al.: Int. J. Psychiatry Med., 34: 83-9, 2004. 
37- SHORVON S.D.: Handbook of epilepsy treatment. 3 ed Hoboken, USA: Wiley-Blackwell, 2010, 2010.

38- ANDRADE R.J., LUCENA M.I., FERNANDEZ M.C., VEGA J.L. and CAMARGO R.: Dig. Dis. Sci., 46: 1416$9,2001$.

39- GAHR M., et al.: Pharmacopsychiatry, 46: 214-20, 2013.
40- TAYLOR D., PATRON C. and SHITIJ K.: Maudsley prescribing guidelines. 10 ed. London, England: Informa Healthcare, 2009.

41- MARWICK K.F., TAYLOR M. and WALKER S.W.: Clin. Neuropharmacol., 35: 244-53, 2012.

42- PARK S.H. and ISHINO R.: Curr. Drug. Saf., 8: 207-23, 2003.

\section{آمراض الكبد وتداخل الآدوية المعالجة لآمراض آخرى}

تعتبر آمراض الكبد آكثر الآمراض خطورة حيث آنها تمثل المركز الخامس من الآمراض المسبية للوفاة حلل العالم، وتتدرج المشاكل

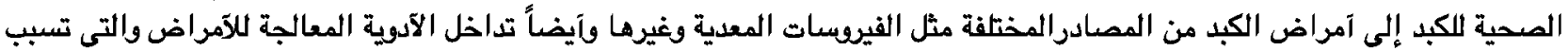

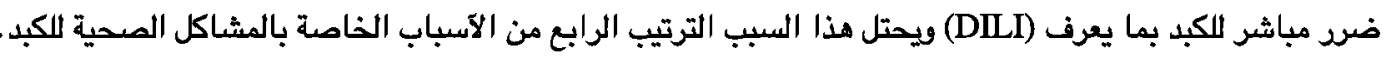

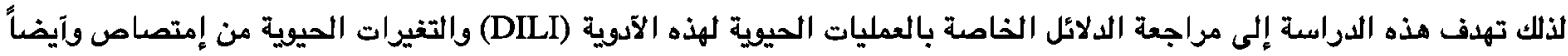

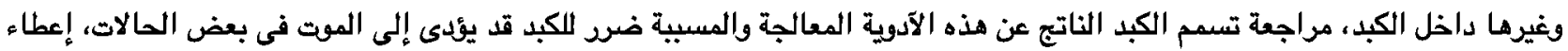
بعض التوصيات والإرشادات المتعلقة بهذه الآدوية المعالجة والمسيبة ضرد لصدية الصدية الكبد وكيفية تقليل مدى خطورتها. 